\title{
PERANCANGAN KAMPANYE MAKANAN BEBAS GLUTEN DAN KASEIN UNTUK ANAK AUTIS DI KOTA BANDUNG
}

\author{
Ismi Endang Sri utami ${ }^{1}$, Yelly Adriani Barlian ${ }^{2}$ \\ ${ }^{1,2}$ Fakultas Industri Kreatif, Universitas Telkom Bandung \\ endangismiutami@gmail.com¹ ${ }^{1}$ yells2003@yahoo.co.uk ${ }^{2}$
}

\begin{abstract}
Abstrak
Autis merupakan salah satu gangguan perkembangan yang ditandai dengan adanya keterlambatan dalam bidang bahasa, prilaku, komunikasi serta interaksi sosial. Jumlah penyandang autis di indonesia setiap tahunnya semakin meningkat, 75-80\% penyandang Autis mengalami rentaldasi mental yang diakibatkan karena kurang kesadaran serta pengetahuan ibu mengenai penerapan makanan bebas gluten dan kasein untuk anak autis, akibat dari makanan yang mengandung gluten dan kasein dapat menambah kehiperaktifan dan bahkan tantrum hebat, maka penelitian ini dilakukan dengan tujuan untuk mengidentifikasi penerapan ibu terhadap makanan bebas gluten dan kasein. Penelitian ini menggunakan metode kualitatif yang dilakukan dengan cara observasi, kusesioner, wawancara, serta studi pustaka yang mana menggunakan analisis matriks dengan perbandingan kampanye sejenis, serta menggunakan strategi komunikasi Facet model of effect. Berdasarkan hasil penelitian ternyata penerapan makanan bebas Gluten dan Kasein ini kerap tidak dapat dilakukan oleh orang tua khususnya ibu dari anak autis sendiri sehingga perlunya penerapan makanan bebas gluten dan kasein yang dilakukan oleh ibu yang memiliki anak autis.
\end{abstract}

Kata Kunci: Autis, Kasein, Gluten, Ibu, Kampanye

\begin{abstract}
Autism is one of the developmental disorder characterized by the presence of delay in the areas of language, behavior, communication and social interaction. The number of people with autism increased every years. $75-80 \%$ persons with Autism experience mental rentaldasi he due to lack of awareness and knowledge about the application of mother food gluten-free and casein for autistic children, a result of foods containing gluten and casein may add kehiperaktifan and even great tantrum, then this research was conducted with the aim to identify the applicability of mothers against food gluten-free and casein. This research was qualitative research we conducted by means of observation and analysis using the matrix with some comparison with mutual campaign and also using facet model of effect model communication strategy. Based on the results of research it turned out that the application of the food is Gluten-free and casein this often cannot be done by parents especially mothers of autistic children themselves so that the necessity of application of food gluten-free and casein made by mothers who have autistic children.
\end{abstract}

Keywords: Autism, Cassein, Gluten, Mother, Campaign 


\section{PENDAHULUAN}

Autisme merupakan salah satu gangguan perkembangan kompleks bahkan dibilang sangat berat yang ditandai dengan keterlambatan dalam bidang kognitif, bahasa, prilaku, komunikasi, serta interaksi sosial (Menurut Yuwono, 2012:26). Sejak tahun 1990 hingga saat ini penyandang autis mengalami peningkatan. Berdasarkan data Anak Center For Disease Control And Prevention yang mengatakan bahwa Autis di Indonesia baik di Dunia mengalami peningkatan yang cukup tinggi. Menurut Wulandari dkk (2012) Indonesia sendiri jumlah penyandang Autis Pada Tahun 2010 terdapat 679.048 jiwa anak penyandang autis. Jumlah penyandang autis banyak terdapat di daerah dengan rasio kepadatan penduduk paling tinggi. Data dari Dinas Sosial Provinsi Jawa Barat tahun 2014 terdapat 31.322 jiwa anak penyandang autis di Jawa Barat. Sedangkan jumlah tertinggi di Jawa barat terdapat di Kota Bandung dengan jumlah 1.075 jiwa anak penyandang autis.

Gejala autis mulai tampak di usia anak 1,5 - 3 tahun, autisme sendiri terlihat dari fisik luar maupun secara mental, kebanyakan penyandang autis akan mengalami degradasi dalam berbagai aspek yang sangat terlihat signifikan jika dibandingkan dengan non autisme. Secara fisik luar autisme menunjukan perbedaan dalam penuturan bahasa, perilaku yang menunjukan seolah-olah mempunyai dunia yang berbeda, serta kesulitan komunikasi secara verbal. Oleh sebab itu menimbulkan kekhawatiran karena diperkirakan $75-80 \%$ berpotensi mengalami retardasi mental. Menurut Kusumayanti (2011) dalam jurnal "Pentingnya Peraturan Makanan Untuk Anak Autis", hal ini disebabkan karena ketidak pedulian orang tua dari anak autis mengenai dampak buruk dari pengaturan makanan bagi anak autis khusunya yang mengandung gluten yang berdampak pada prilaku dan tumbuh kembang anak autis. Destiani Amalia menyatakan bahwa sebanyak $85 \%$ orang tua di kota bandung tidak disiplin dalam pelaksanaan tersebut.

Salah satu tidakan atau usaha yang dilakukan yaitu dengan mengatur makanan untuk anak autis. Makanan untuk anak autis pada umumnya sama seperti makanan anak normal lainnya yang memiki jumlah gizi yang baik dan seimbang dengan energi yang dipakai serta tetap memperhatikan aspek pemilihan makanan. Pada kenyataannya penyandang autis memiliki kehiperaktifan yang cukup tinggi, yang dapat disebabkan oleh makanan. Dengan mengikuti pedoman peraturan makanan untuk anak autis salah satunya adalah memberikan karbohidrat pilihan yang bebas dari gluten dan kasein. Dengan melakukan kerjasama dengan keluarga akan mempermudah dalam menerapkan peraturan makanan pada anak autis. Selain itu kesulitan orang tua khususnya ibu dalam menyiapkan makanan yang tidak mengandung gluten, salah satunya karena ketidak tahuan ibu dalam menemukan sumber pengganti makanan yang tidak mengandung gluten. Banyak sekali sumber pengganti gluten yang memang harganya cukup terjangkau namun karena kurangnya informasi mengenai bahayanya gluten jika terus dikonsumsi oleh anak autis, sehingga informasi tidak tersampaikan kepada ibu yang memiliki anak autis. Namun sebagian ibu mengetahui penerapan makanan tidak mengandung gluten tapi sulit untuk di terapkan karena tindakan serta sikap disiplin pada anaknya. 
Melihat betapa pentingnya melakukan pembebasan makanan gluten dan kasein untuk anak autis sendiri, maka perlunya kampanye sosial yang dapat meningkatkan kesadaran orang tua terhadap makanan yang mengandung gluten khususnya ibu. Dengan meningkatkan kedisiplinan dari pengetahuan yang telah dimikili serta dapat menginformasikan kepada ibu untuk melakukan tndak pencegahan terhadap peran dalam memilih makanan yang mengandung gluten. Semakin banyak penyandang autisme khususnya di kota Bandung maka akan semakin banyak pula ketidak tahuan ibu terhadap tingkat kedisplinan pemberian makanan pada anaknya.

Sehingga kampanye sosial ini untuk mengajak ibu mengenali makanan yang tidak mengandung gluten dan kasein dan mengajak untuk melakukan prilaku disiplin terhadap kesadaran ibu dalam memeberikan makanan pada anak autis. Dengan harapan ibu lebih peduli terhadap gizi anak sehingga perilaku serta perkembangan anak autis dapat kembali normal jumlahnya tinggi.

\section{METODE PENELITIAN}

Dalam topik ini penulis merancang kampanye makanan bebas gluten dan kasein untuk anak autis, penulis menggunakan pendekatan analisis Matriks. Matriks terdiri atas kolom dan baris yang dimana masing masing kolom dan baris tersebut mewakili dua dimensi yang berbeda beda, dapat berupa sebuah informasi serta konsep. Juxtaposition atau membandingkan sebuah prinsip dari matriks yang dilakukan dengan cara menjajarkan. Sehingga menjadi sebuah tolak ukur dalam penganalisisan (Widiatmoko, 2013). Menurut Rohidi, 2011 :247 dalam buku Widiatmoko Didit, matriks merupakan salah satu metode analisis yang bermanfaat dan dapat digunakan untuk menyampaikan informaso dalam bentuk ruang yang padat. Salah satu alat untuk menganalisis yang baik digunakan dalam pengelolahan informasi maupun menganalisis.

Analisis dari kampanye sentuhan ibu dan autism is not a joke sebagai salah satu kampanye sejenis digunakan sebagai analisis data. Melalui observasi, wawancara, kuesioner serta studi pustaka. Dengan memakai metode penelitian kualitatif sehingga dapat memecahkan masalah dan menentukan target audience dan, oleh sebab itu metode penelitian ini dilakukan dengan cara observasi secaralangsung agar mendapatkan data mengenai penerapan ibu terhadap pemberian makanan kepada anak autis sendiri, selain itu untuk mendapatkan data penggunaan makanan bebas gluten dan kasein ini dilakukan lah kuesioner yang dapat memperkuat hasil penelitian yaitu mendapatkan hasil menyebutkan bahwa $65 \%$ pengetahuan, $58 \%$ sikap serta 39 $\%$ tindakan orang tua khususnya ibu dalam pemberian makanan pada anak autism berada dalam kategori yang cukup. 


\section{Observasi}

Teknik pengamatan dilakukan di Yayasan serta sekolah luar biasa lalu dengan melakukan pengamatan kepada Ibu ber usia 23-40 tahun yang memilki anak autis yang dengan kelas sosial ( $S E S A B$ ) yang kurang memiliki pengetahuan tentang gluten.

2. Wawancara

Wawancara ini dilakukan kebeberapa narasumber yaitu Ahli Gizi, Yayasan Autis, Sekolah luar biasa Autis, Ibu yang memilki anak autis, baik secara langsung dan tidak langsung.

3. Kuesioner

Kuesioner merupakan bagian dari survei dari topik yang akan diangkat. Pertanyaan kuesioner ini dilakukan kebeberapa ibu anak autis, tempat melakukan pengisian kuesioner di berbagai Yayasan autis dan SLB.

4. Studi Pustaka

Teknik pengumpulan data ini dilakukan dengan mengkaji teori teori yang berhubungan dengan penelitian yaitu teori Kampanye, Teori Autis, teori tentang Gluten, teori periklanan, teori desain komunikasi visual. Dalam melakukan pengumpulan data peneliti mengumpulkan data dari jurnal, artikel serta hasil penelitian yang bersumber dari internet.

\section{HASIL DAN PEMBAHASAN}

Berdasarkan dari data data yang ditemukan di dalam observasi, wawancara, kuesioner dan studi literatur penelitian ini kemudian meneliti data data tersebut dan mendeskripsikannya. Dari hasil data dari wawancara kepada Dr Dewi salah satu ahli gizi yang mengatakan bahwa memang perlunya penanganan khusus untuk anak autis dalam penerapan makanan bebas gluten dan kasein. Sebanyak $85 \%$ orang tua khususnya ibu sangat tidak disiplin dalam penerapan makanan tersebut.

Dari data hasil observasi kepada khalayak sasaran menemukan sebuah pesan serta visual yang sesuai dengan penelitaian yang kemudian dapat dsimpulkan bahwa khalayak sasaran membutuhkan suatu solusi yang tepan dan informasi yang dapat digunakan sebagai bantuan uantuk melaksanakan penerapan makanan bebas gluten dan kasein ini kepad ank anaknya. Yang mana targe sarasaran yaitu:

a. Demografis

Jenis kelamin : Perempuan

Usia : Ibu rumah tangga 23-40 tahun

Pendidikan : Semua pendidikan

Tingak Ekonomi : Ses AB

b. Geografis : Bandung

c. Psikografis : Mengikuti perkembangan jaman, rasa ingin tahu yang tinggi tentang bahan makanan yang mengandung gluten dan kasein peduli terhadap gizi anaknya

Berdasarkan hasil analisis data yang dilakukan oleh penulis maka pesan yang Pesan yang akan disampaikan kepada khalayak sasaran merupakan hasil dari data observasi 
dan kuesioner yang dilakukan kepada ibu ibu yang memiliki anak autis sesuai dengan target sasaran. Berdasarkan hasil observasi dan kuesioner bahwa ibu memiliki gaya hidup yang cukup sibuk untuk mengurusi urusan rumah tangga sehingga mereka lupa akan aturan makan untuk anak autis yang disama ratakan dengan anggota keluarga lain yang alasnya karena riber, susah dan tidak tahu tentang makanan pengganti dari anak autis itu sendiri. Solusi dari kampanye ini adalah memeberikan tahu kepada khalayak sasaran dan melaksanakan penerapan makanan yang mengandung gluten dan kasein, yaitu " bebas cemas tanpa gluten"

Pada perancangan kampanye ini dibutuhkan sebuah nama yang akan menjadi bagian dari logo kampanye. Nama untuk kampanye sosial ini yang bernama "Teman Ibu" kepanjangan dari "Tenang dan nyaman untuk ibu" yang menjelaskan tentang kecemasan dari ibu sehingga ibu tidak perlu khawatir lagi dengan adanya kampanye ini ibu akan mendapatkan informasi mengenai makanan yang bebas dri gluten dan kasein.

Dalam proses pembuatan kampanye ini, selain massage dari kampanye ini yang mana pesan ini akan dijadikan sebuah Tagline yang dapat digunakan untuk penyederhanaan pesan sehingga mendapatkan perubahaan kata menjadi lebih sederhana dan mudah diingat sehingga pesan yang disampaikan akan lebih efektif dan efisien sehingga pesan yang disampaikan akan lebih mudah diingat. Tagline yang digunakan "anak istimewa tanpa gluten" Kata "Anak Istimewa" yang menekan kan bahwa anak istimewah berasal dari kata anak autis sendiri karena sebagian orang yang masih berpikir bahwa anak autis itu berbeda nah dari sini muncul sebuah kata yang istimewah. Sedangkan "Tanpa gluten" digunakan untuk menekankan kepada khalayak sasaran yang masih berpikir bahwa makanan yang mengandung gluten dan kasein itu sangat penting jika di hindari oleh anak autis, oleh sebab itu ibu harus membebaskan makanan makanan yang mengandung dua bahan itu dapat di hilngkan dari menu makanan untuk anak autis, kenapa hanya memakai gluten saja sebab bahan makanan yang paling dikonsumsi untuk anak autis sendiri bahan yang banyak mengandung gluten.

Dalam Kampanye ini digunakan metode Facet menurut Moriarty dkk 2009 Facet Model Of Effects merupakan model komunikasi dalam advertising yang meningkatkan proses kognitif dan dapat merubah sehingga perubahan tersebut dapat membuat menjadi lebih baik berikut paparan : 


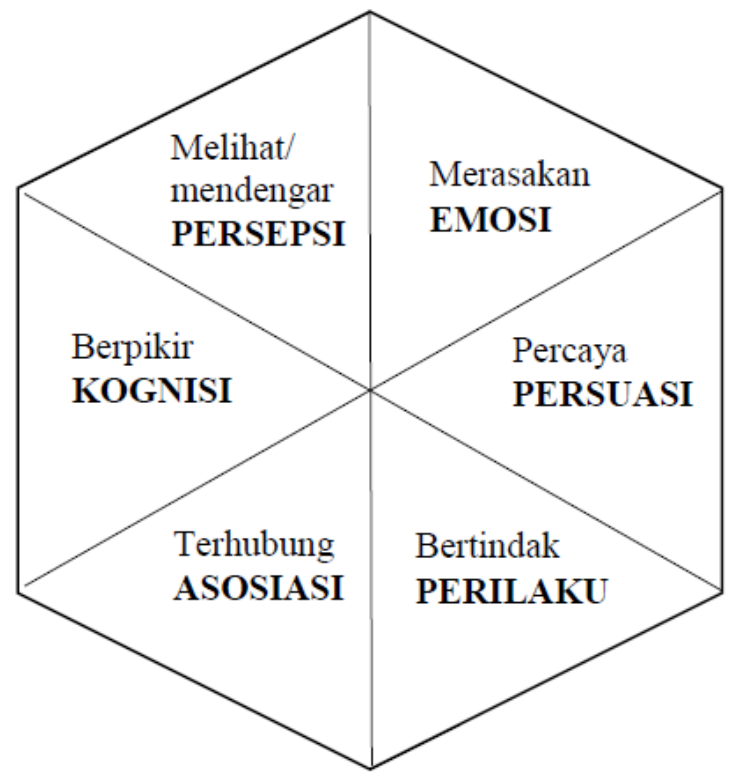

Bagan 1. Facet Model of Effect

Sumber: Moriarty, Sandra. 2011:134

1. Perception, persepsi merupakan suatu proses sehingga kita dapat menerima pesan yang disampaikan melalui indra kita senggga dapat effektif.

2. Emotion, emosi merasakan respon yang paling efektif untuk mencerminkan tentang perasaan sesuatu, sehingga dapat menstimulasi keinginan dan mnyentuh emosi sehingga menciptakan suatu rasa suka dan menimbulkan perasaan.

3. Kognisi, bagai mana cara konsumen berpikir, untuk mencari sebuah informasi atau merespon informasi bagaimana cara belajar dan memahami sesuatu sehingga dapat membuat respon rasional terhadap pesan yang disampaikan

4. Asosiation, asosiasi suatu teknik komunikasi yang merupakan salah satu symbol, sehingga adanya hubungan komunikasi dengan kampanye yang dilakukan, untuk menarik perhatian melalui media social.

5. Persuation, persuasi cara komunikasi untuk meningkatkan kesadaran suatu pihak sehingga dapat mempengaruhi dan memotivasi pihak lainnya agar mereka percaya dan mau melakukan sesuatu, shingga dapat menciptakan keyakinan

6. Behavior, prilakuku dengan cara memberikan tindakan langsung dan menunjukan bahwa dapat berinteraksi dengan khalayak sasaram, sehingga dengan adanya tindakan langsung ini dapat merepresentasikan respon langsung

\section{Creative Brief}

Pelaksanaan kreatif yang dapat dipaparkan dalam sebuah creative brief, yang dapat digunakan untuk memaparkan kreatifitas kreatifitas dari penulis. Creative breif biasanya berupa dokumen yang berisi ringkasan dari strategi advertising dan marketing, ada beberapa yang harus dilakukan ketika membuat Creatif brief (Moriarty, dkk 2011: 436-438) 


\section{Problem}

Kurangnya pengetahuan serta tindak kesadaran orang tua khususnya ibu terhadap pencegahan makanan yang mengandung gluten dan kasein untuk anak autis. Karena ketidak tahuan tersebut dan tingakat kesadaran yang rendah sehingga banyak orang tua yang masih belum mengetahui tentang bahaya jika terus dikonsumsi oleh anak autis.

\section{Why do we advertise?}

Dengan membuat sebuah kampanye ini penulis memiliki tujuan untuk membangun tingkat kesadaran serta pngetahuan orang tua tentang makanan serta membantu penyembuah anak autis agar negara ini memiliki bangsa yang cerdas.

\section{Insight}

Memiliki keinginan untuk informasi mengenai makanan yang tidak mengandung gluten dan kasein, ingin ada pengganti makanan yang bebas gluten dan kasein dan adanya makanan yang bebas dari gluten dan kasein sehingga anak menjadi lebih tenang.

\section{What do we want them in think or do?}

Dengan adanya pengganti makanan bebas gluten dan kasein menjadikan khalayak sasaran tidak cemas dan khawatir untuk anaknya menjadi hiferaktif, tantrum dan retardasi mental.

\section{What to say?}

"Bebas Cemas dengan Tanpa Gluten"

\section{Why should anyone believe it?}

Kurangnya pengetahuan dan kesadaran orang tua yang dapat menyebabkan penanganan ana autis yang mengatakan $75-80 \%$ terkena retardasi mental yang disebabkan prilaku orang tua terhadap pemberian makan kepada anak autis

\section{Time and Manner?}

Edukasi, rasional, emosional

\section{Mandatories}

Logo dari kampanye, Logo dari komunitas autis beserta Logo dari berbagai pihak terkait.

\section{Big Idea Campaign}

"Teman Ibu"

(Tenang dan aman untuk Ibu) 


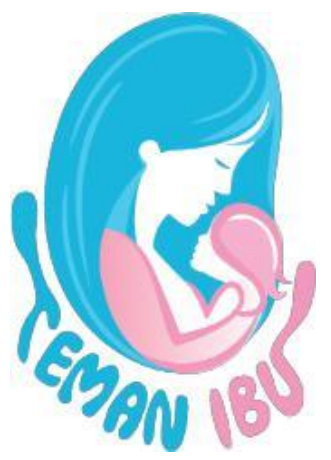

Gambar 1. Logo

Sumber: Ismi Endang Sri Utami, 2017

Logo yang terpilih ini merupakan salah satu logo yang menggambarkan kasih sayang dari ibu, mulai dari warna hingga bentuk tipografi, dengan kombinasi warna yang digunakan menggunakan warna warna yang cerah, sesuai dengan target audiens dan moodboard dari target audiens yang mana warna pink merupakan warna yang menggambarkan kasih sayang, sedang kan biru menggambarkan keceriaan.
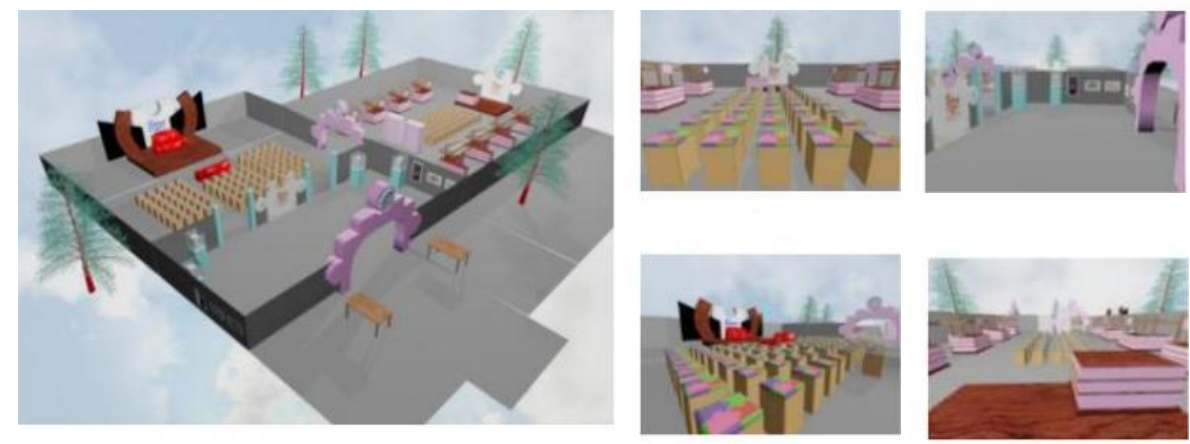

Gambar 2. 3D Event

Sumber: Ismi Endang Sri Utami, 2017
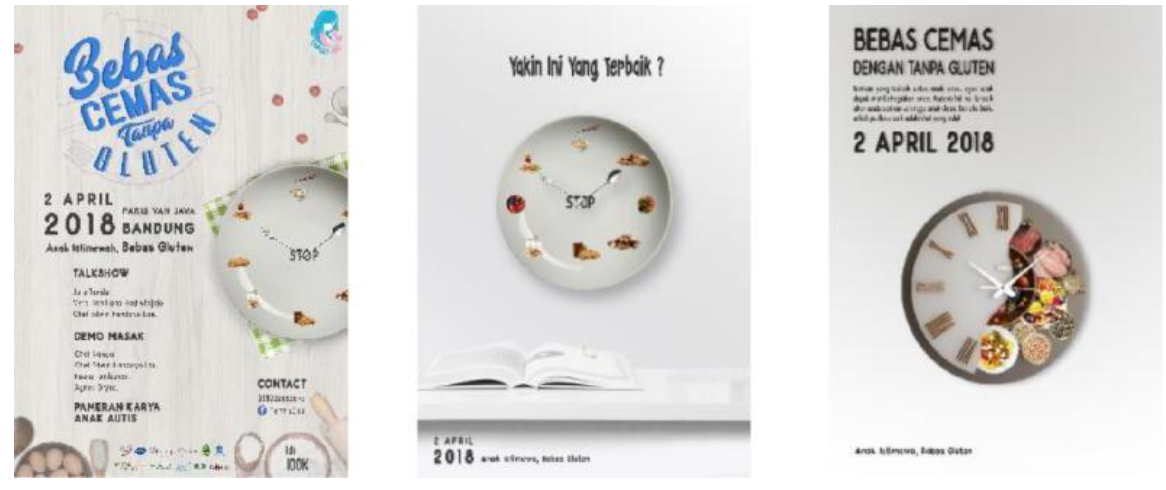

Gambar 3. Poster Event

Sumber: Ismi Endang Sri Utami, 2017

Poster Event merupakan salah satu poster utama dari kampanye ini. Dengan menggunakan konsep yang dinamis dan secara langsung agar pesan tersampaikan cukup ringan sesuai dengan acara dari event yang berlangsung dengan menggunakan 
teknik fotografi, dengan memberikan kesan saling bekerja sama dan saling mengingatkan akan bahaya dari makanan bebas gluten dan kasein sehingga khalayak sasan dapat merasakan visual yang ditimbulkan dalam kampanye ini.
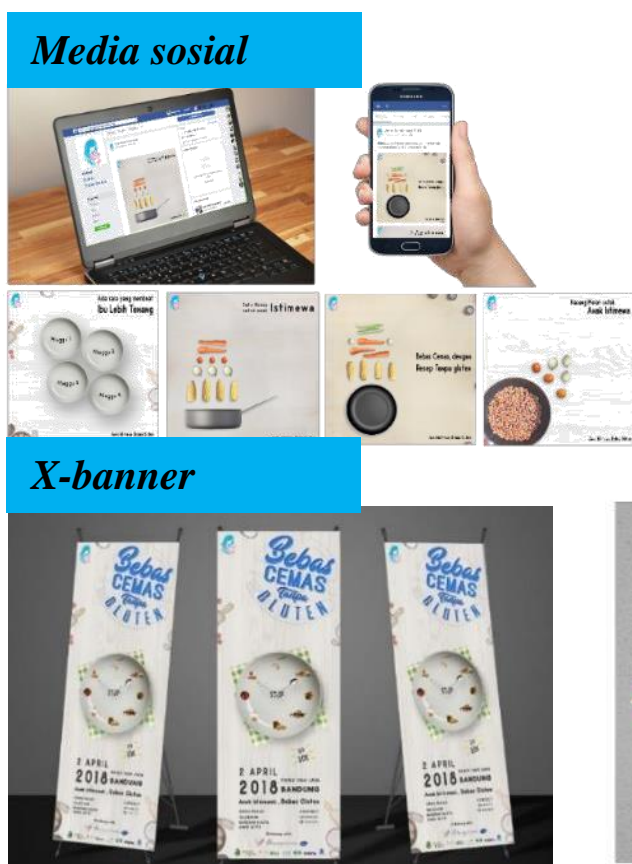
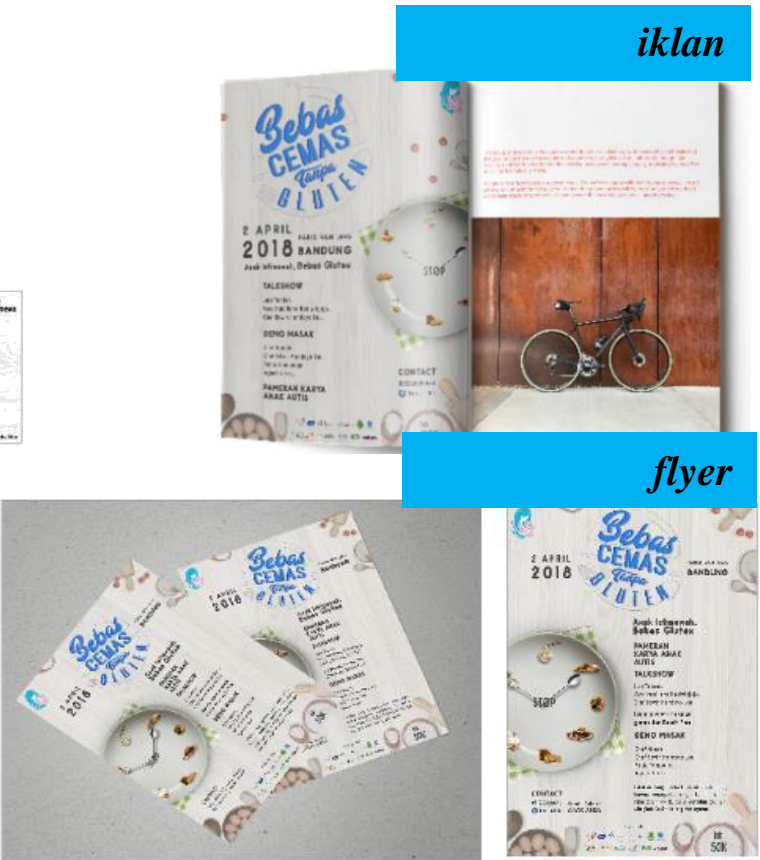

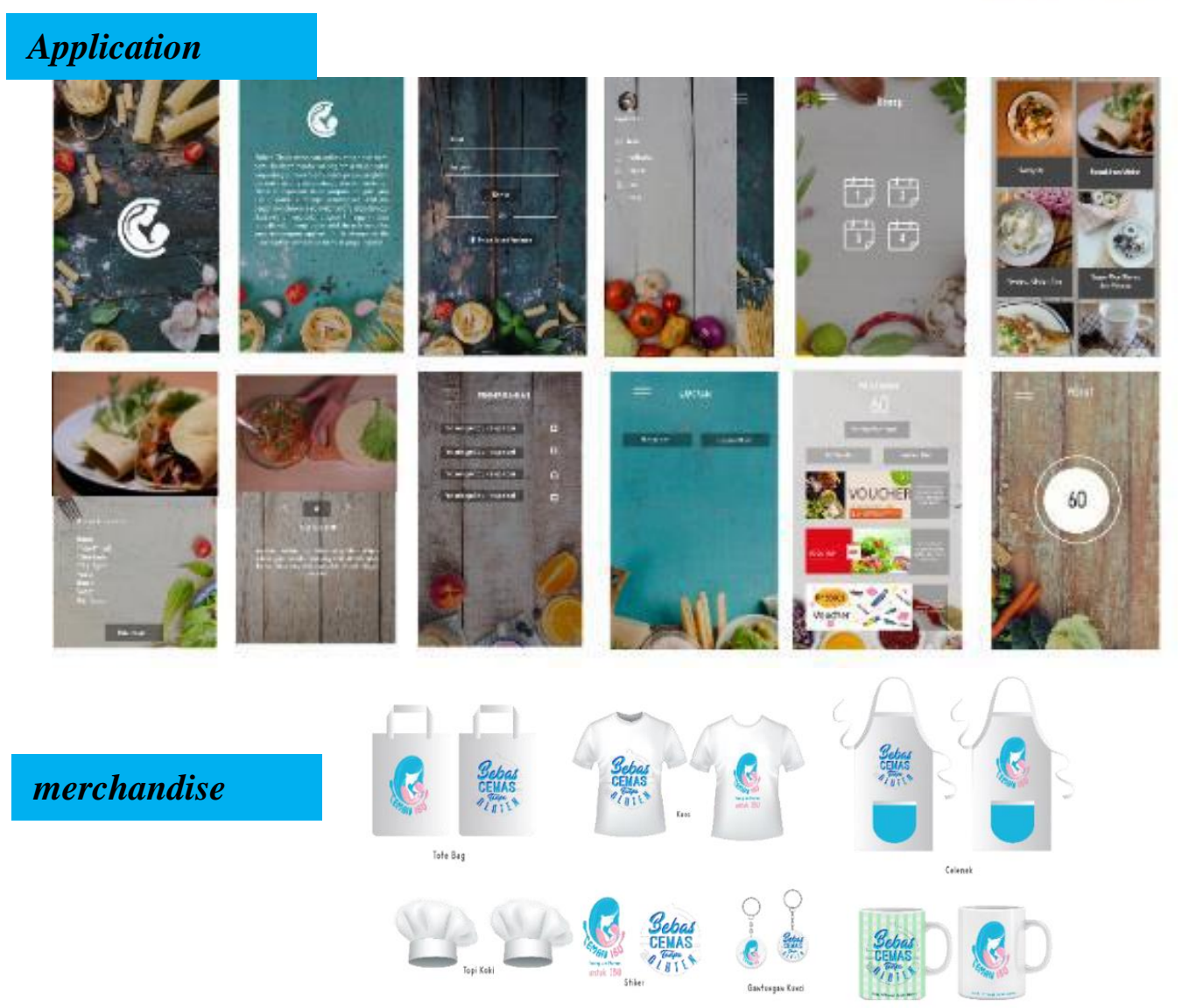

Gambar 4. Berbagai media kampanye Sumber: Ismi Endang Sri Utami, 2017 


\section{KESIMPULAN}

Penyandang Autis di Indonesia semakin hari semakin meningkat khususnya di kota Bandung yang menjadi salah satu tingkat penyandang autis paling tinggi. Bahkan hingga sampai saat ini tercatat $75-80 \%$ penyandang autis mengalami rentaldasi mental yang disebabkan oleh pengaruh makanan yaitu makanan yang mengandung gluten dan kasein, selain itu penggunaan bahan makanan yang mengandung gluten dan kasein dapat menyebabkan anak semakin hiperaktif, tantrum dan bahakan tertawa sendiri. Kurangnya kesadaran dan pengetahuan yang diakibatkan karena kurang perhatian pemerintah dalam memberikan nformasi mengenai bahan makaan ini kepada ibu-ibu yang memiliki angka autis.

Agar ibu mengetahui dan menyadari makanan yang mengandung gluten maka perlunya sebuah kampanye yang dapat membantu dalam meningkatkan kesadaran dan pengetahuan khalayak sasaran maka dibuatlah sebuah kampanye yaitu "Teman Ibu (tenang dan nyaman untuk ibu)" yang ditujukan kepada ibu yang memiliki anak autis dengan kisaran umur 27-40 tahun. Komunikasi yang dilakukan melalui media utama yaitu even serta media pendukung lainnya, dengan harapan akan menimbulkan kesadaran serta menambah pengetahuan ibu mengenai bahan makanan yang bebas dari gluten.

\section{DAFTAR PUSTAKA}

Angraini, Lia dan Kirana, Nathalia. 2014. Desain Komunikasi Visual Dasar-Dasar Panduan Untuk Pemula. Bandung: Nuansa Cendikia.

Damayanti, Sri. 2012. Prilaku Pemilihan Makanan Dan Diet Bebas Gluten Dan Kasein Untuk Anak Autis. Semarang: Ilmu Gizi Universitas Diponegoro Semarang.

Destiani, Amalia., Ropi, Helwiyah dan Mardhiyah, Ai. Kepatuhan Orang Tua Dalam Menerapkan Terapi Diet Gluten Free Casein Free Pada Anak Penyandang Autisme Di Yayasan Pelita Hafizh Dan Slbn Cileunyi Bandung. Bandung: IImu Keperawatan Universitas Padjadjaran.

Effendi, Febriyanti. 2014 .Pengetahuan Ibu, Pola Asuh Makan Dan Pola Konsumsi Gluten Kasein Pada Anak Autis Di Jakarta Dan Bogor. Bogor: Ekologi Manusia Institut Pertanian Bogor.

Kusumayanti, Dewi. 2011. Pentingnya Pengaturan Makan Untuk anak Autis. Denpasar : Jurnar Ilmu Gizi. Vol. 2 No 1:1-8.

Moriarty, Mitchell, dan Wells. 2011. Advertising Edisi Kedelapan. Jakarta: Kencana.

Prima, Betha. 2016. Tentang Bimbingan Intensif Melalui Media Edukasi Untuk Orang Tua Anak Autisme Di Kota Bandung. Banndung: Universitas Pasundan Bandung

Widiatmoko, Didit. 2013. Metodologi Penelitian Visual. Bandung: Dinamika Komunika Wulandari, Kusuma., Astini, Natha dan Utami, Cahya. 2013. Pengaruh Terapi Musik Klasik Terhadap Kemampuan Bahasa Pada Anak Penderita Autisme Di Sekolah Kebutuhan Khusus Denpasar Tahun 2012. Denpasar : IImu Keperawatan. Vol 1 No 2 :1-8.

Yuwono, Joko. 2012. Memahami Anak Autistik. Bandung : Alfabeta 